Portland State University

PDXScholar

7-3-1975

\title{
The Relative Social Acceptability of Three Types of Alaryngeal Speech
}

\author{
Kathleen Dawn Stewart \\ Portland State University
}

Follow this and additional works at: https://pdxscholar.library.pdx.edu/open_access_etds

Part of the Speech Pathology and Audiology Commons Let us know how access to this document benefits you.

\section{Recommended Citation}

Stewart, Kathleen Dawn, "The Relative Social Acceptability of Three Types of Alaryngeal Speech" (1975). Dissertations and Theses. Paper 2417.

https://doi.org/10.15760/etd.2414

This Thesis is brought to you for free and open access. It has been accepted for inclusion in Dissertations and Theses by an authorized administrator of PDXScholar. For more information, please contact pdxscholar@pdx.edu. 
AN ABSTRACT OF THE THESIS OF Kathleen Dawn Stewart for the Master of Science in Speech Communication: Fmphasis in Speech Pathology/Audiology presented July 3, 1975.

Title: The Relative Social Acceptability of Three Types of Alaryngeal Speech.

APPROVED BY MEMBERS OF THE THESIS COMMITTEE:
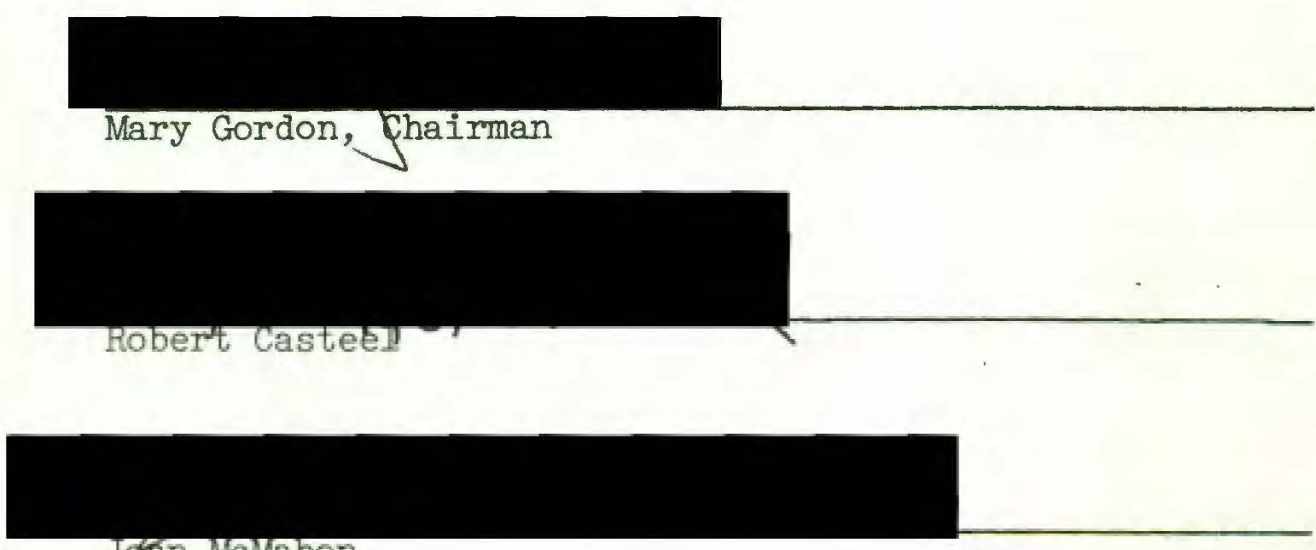

Joan MoMahon

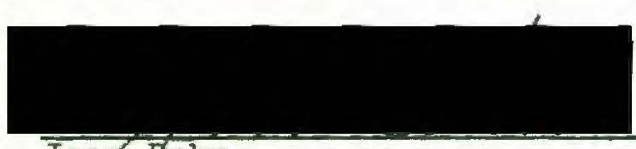

Joax pehn

As a result of the surgical removal of the larynx, the laryngectomee is no longer able to speak and must choose to learn a new method of oral cormunication if he wishes to communicate orally. Laryngectomees, speech clinicians and physicians need to be provided with information which will assist in the selection of the most appropriate type of alaryngeal speech for each individual. Social acceptability is one criterion which may be an important consideration. This study, therefore, compared 
three modes of alaryngeal speech: Asai, esophageal, and artificial larynx, on the parameter of social acceptability.

Specifically, this study proposed to determine which type of alaryngeal speech is most socially acceptable to a naive listening sample. Answers to the following questions were sought:

1. Which type of alaryngeal speech is most socially acceptable to the naive listener?

2. What is the rank order of social acceptability of the three types of alaryngeal speech as rated by naive judges?

3. Do naive judges rate female and male alaryngeal voices similarly?

4. Do male and female judges rate alaryngeal voices in the same manner?

The subjects for this sudy were twelve alaryngeal speakers: four Asai, four artificial larynx, and four esophageal speakers. Each alaryngeal group was representcd by one female and three male speakers judged to be "good" or "effective" speakers.

The subjects were tape recorded while reading the first paragraph of the Rainbow Passage from which the second sentence from each voice sample was extracted and arranged in three sections on an audio-tape which was presented to judges. In the first section, the voices were arranged and presented in random order to acquaint the judges with the range of voices being judged. In the second section, the voices were presented in a different random order. The judges rated the voices in this presentation on the parameter of relative social acceptability using a seven-point rating scale. In the third section, the judges listened to triads (groups of three) of voices and rank ordered the voices within each triad in order of social acceptability. Each triad con- 
tained a member from each alaryngeal speech group, with the voices within each triad arranged in random order. Twenty-seven triads were composed of male voices and six of female voices. The results were analyzed to determine if any statistically significant differences exist in the speech social acceptability of esophageal, artificial larynx, and Asai speech.

The findings indicate sex of the judges did not influence the rating scores assigned to the voices. Male and female judges rated the alaryngeal speakers in a like manner, neither groups scoring the voices higher or lower than the other.

Analysis or the rating scale data revealed no statistically significant differences in the scores generally assigned male and female speakers. Neither male nor female speakers received higher ratings. According to the mean scores of the alaryngeal groups obtained from the rating scale data, esophageal speech was the preferred method of alaryngeal speech on the parameter of social acceptability. This was not a statistically significant preference when considering male and female speakers together but merely a trend. However, when considering the male speakers alone, a statistically significant difference was found among the groups with the order of social acceptability being: 1) esophageal, 2) Asai, and 3) artificial larynx. The ranking data indicated male and female speakers are ranked in different orders of social acceptability. The female speakers were ranked as follows on the parameter of social acceptability: 1) Asai, and 2) esophageal and artificial larynx (ranked equal).

The size of the sample requires the results obtained to be viewed 
as trends. Replication of this study using a larger sample should be completed to confirm the results. 
THE RELATIVE SOCIAL ACCEPTABILITY

OF THREE TYPES OF ALARYNGEAL SPEECH

by

KATHLEEN DAWN STEWART

A thesis submitted in partial fulfillment of the requirements for the degree of

MASTER OF SCIENCE IN SPEECH COMMUNICATION:

EMPHASIS IN SPEECH PATHOLOGY/AUDIOLOGY

Portland State University

1975 
TO THE OFFICE OF GRADUATE STUDIES AND RESEARCH:

The members of the Committee approve the thesis of

Kathleen Dawn Stewart presented on July 3, 1975.

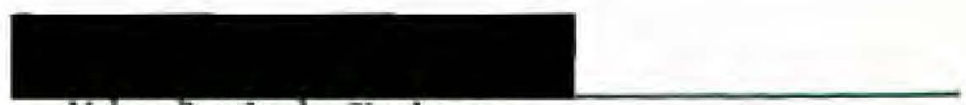

Mary Gordons Chairman
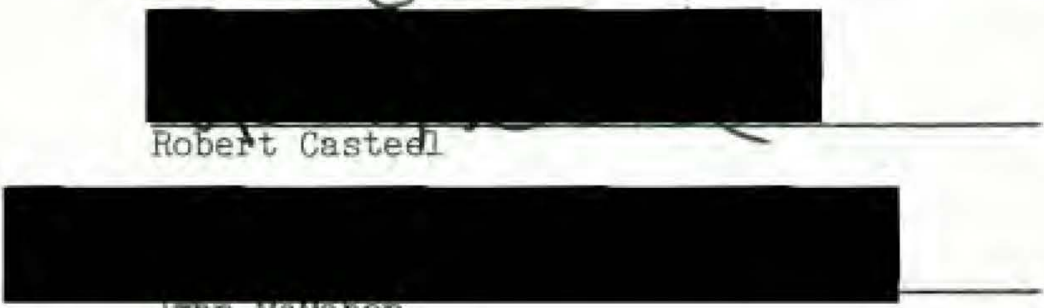

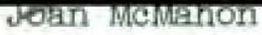

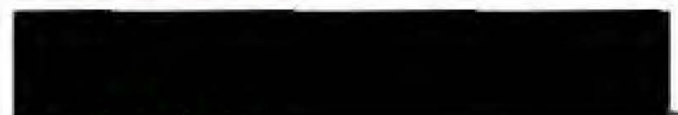

Joar) Behn

APPROVED:
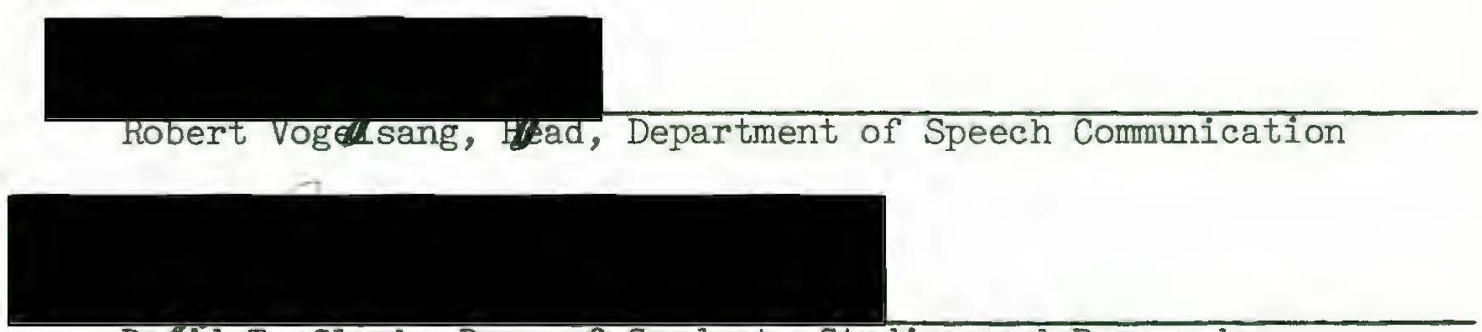

David T. Clark, Dean of Graduate Studies and Research

August 1, 1975 


\section{ACKNOWLEDGMENTS}

The completion of this project would not have been possible without the encouragement, assistance, and guidance I received from so many friends.

I wish to thank the alaryngeal speakers who so graciously allowed me to enter their homes and collect the voice samples needed for this study.

My sincere gratitude must be expressed to Cheryl Schultz, a fellow student, for the initial inspiration to conduct research in this area and for so cooperatively providing me with voice samples of Asai speakers.

Further expression of appreciation goes to the members of my thesis committee, Joan McMahon, Robert Casteel, and Joan Behn, for their interest and constructive comments.

Special acknowledgment is gratefully made for the direction and moral support provided by Mary Gordon, my academic advisor and chairman of my thesis committee. Except for her patience and many hours of untiring assistance and guidance, this project would undoubtedly be unfinished at this time.

Lastly, to my parents, Jerry and Audrey Stewart, goes my deepest gratitude and love. They have continually demonstrated their interest and concern for me and my education, not only with their financial support, but also with their enthusiastic encouragement, expression of confidence, and supportive love. 
TABLE OF CONTENTS

PAGE

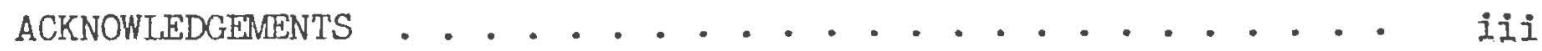

LIST $\mathrm{OF}$ TABLES ............................ vi

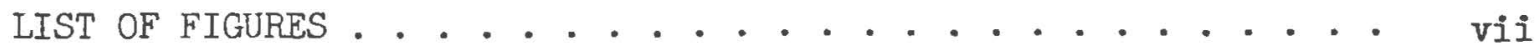

CHAPTER

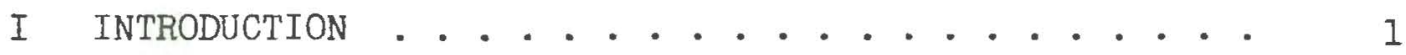

Statement of Purpose.......... 5

II REVIEW OF THE LITERATURE . . . . . . . . . . . 6

Methods of Alaryngeal Speech . . . . . . . 6

Esophageal Speech

Artificial Larynx

Asai Speech

Characteristics Related to Learning Alaryngeal

Speech . . . . . . . . . . 15

Intelligibility and Social Acceptability Studies . 16

Summary ............. 2 20

III METHODS AND PROCEDURES . . . . . . . . . . 22

Methods .............. . 22

General Plan of Study

Subjects

Judges

Instrumentation

Procedures ............. . . . 24 24

Recording and Presentation Procedures

Rating Procedures

Data Analysis 
IV RESULTS AND DISCUSSION

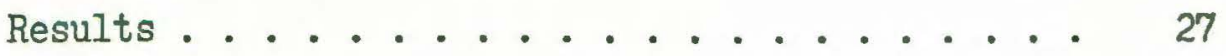

Discussion ............. 34

V SUMMARY AND IMPLICATIONS . . . . . . . . . . . 38

Summary .. . . . . . . . . . . . 38

Implications .............. 40

Clinical

Research

SELECTED BIBLIOGRAPHY . . . . . . . . . . . . . . . . 43

APPENDICES . . . . . . . . . . . . . . . . . . . . 4 46 


\section{LIST OF TABLES}

TABLE

PAGE

I Rating Scale Intrajudge Reliability . . . . . . . . 28

II Rating Scale Interjudge Reliability . . . . . . . 29

III One Way Analysis of Variance of Rating Scale Data . . 30

IV Intergroup Comparisons of Social Acceptability. . . . . 31

V Group Mean Scores from Rating Scale Data. . . . . . 32

VI Influence of Subject Sex on Scores Obtained . . . . . 32

VII Influence of Judge Sex on Scores Assigned . . . . . . 33 
1 The head and neck before and after total laryngectomy .

2 The head and neck after Asai surgery. . . . . . . 
CHAPTER I

\section{INTRODUCTION}

The first laryngectomy, the surgical removal of the larynx, was performed by Billroth in 1873. By 1890 at least two hundred laryngectomies had been performed (Gilchrist, 1973; Snidecor, 1968). Since that time, the number has increased dramatically. Snidecor (1968) reported on the results of a survey conducted in 1967 by the American Cancer Society which showed there were approximately 23,000 laryngectomees (persons who had undergone a laryngectomy) alive in the United States. Each year 2,000 additional surviving laryngectomees are added to this number. Looking at the United States population, the total incidence of laryngectomees is approximately 4 adults per 100,000 . The ratio of men to women is approximately $10: 1$.

The laryngectomee has a number of physiological, psychological and social adjustments with which to contend. Hunt (1964) discussed the allencompassing factors faced by the laryngectomee and stated that laryngectomy produces more profound physiological and psychological changes in patients than any operation. The laryngectomee awakens unable to talk; his breathing mechanism is altered so he is now breathing through a tracheostoma in his neck; his senses of taste and smell are diminished; and there is the fear of recurring cancer. These combined changes create fear about the future.

The physiological changes which occur as a result of a laryngectomy affect the respiratory system. Normally the trachea, which connects the 
mouth and nose to the lungs, and the esophagus, which connects the mouth to the stomach, merge in the pharynx. When the larynx is removed in a total laryngectomy, the trachea, which is severed below the larynx, is bent forward and sutured to a hole created in the neck just above the sternum forming a tracheal stoma. The laryngectomee no longer breathes through the normal respiratory channel, i.e., the mouth, nose, and pharynx; instead the stoma becomes the direct connection to the lungs (Figure 1). Negus (1929) listed nine functions of the larynx including respiration, all of which are altered as a result of a laryngectomy: 1) respiratory, 2) protective, 3) circulatory, 4) fixitive, 5) deglutitory, 6) tussive, 7) expectorative, 8) emotional, and 9) phonatory. As a result of the surgery, the laryngectomee is no longer able to speak and must choose a new method of oral communication if he wishes to. communicate orally. According to Lauder (1969), 79 percent of laryngectomees learn to speak by some method. Until recently, two primary methods of alaryngeal speech have been used extensively: .I) esophageal voice and 2) the artificial larynx. Currently, a third method, Asai speech, developed by Dr. Ryozo Asai is being used as well (Perkins, $1971)$.

In addition to the physiological changes to which the laryngectomee must adapt, he faces a.variety of additional problems during rehabilitation, such as economic, social, sexual, health, and appearance. Because of the lower pitch level characteristic of esophageal speech (the most common type of alaryngeal speech), women laryngectomees face the additional problem of adjusting to a masculine-sounding voice. Gardner (1966) found married women adjust better than single women. All 


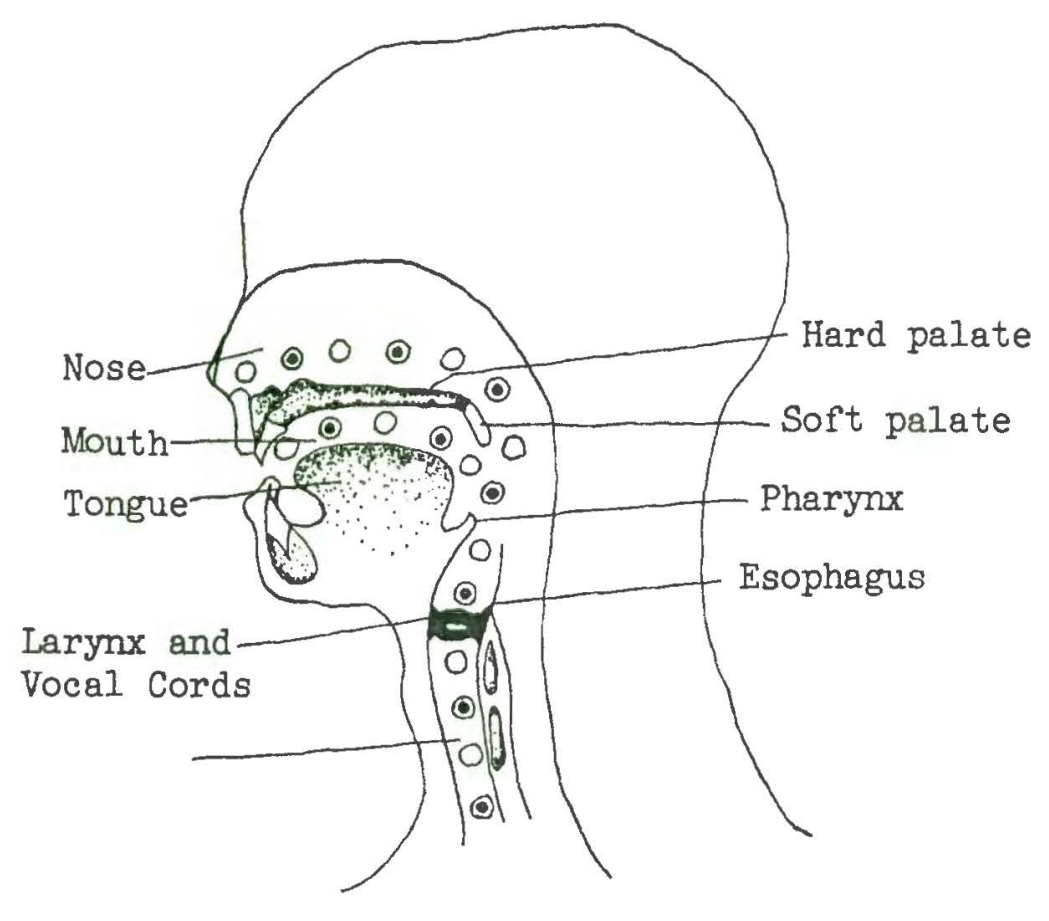

Phonic air 000 Pulmonary air $\bigcirc \odot \odot$

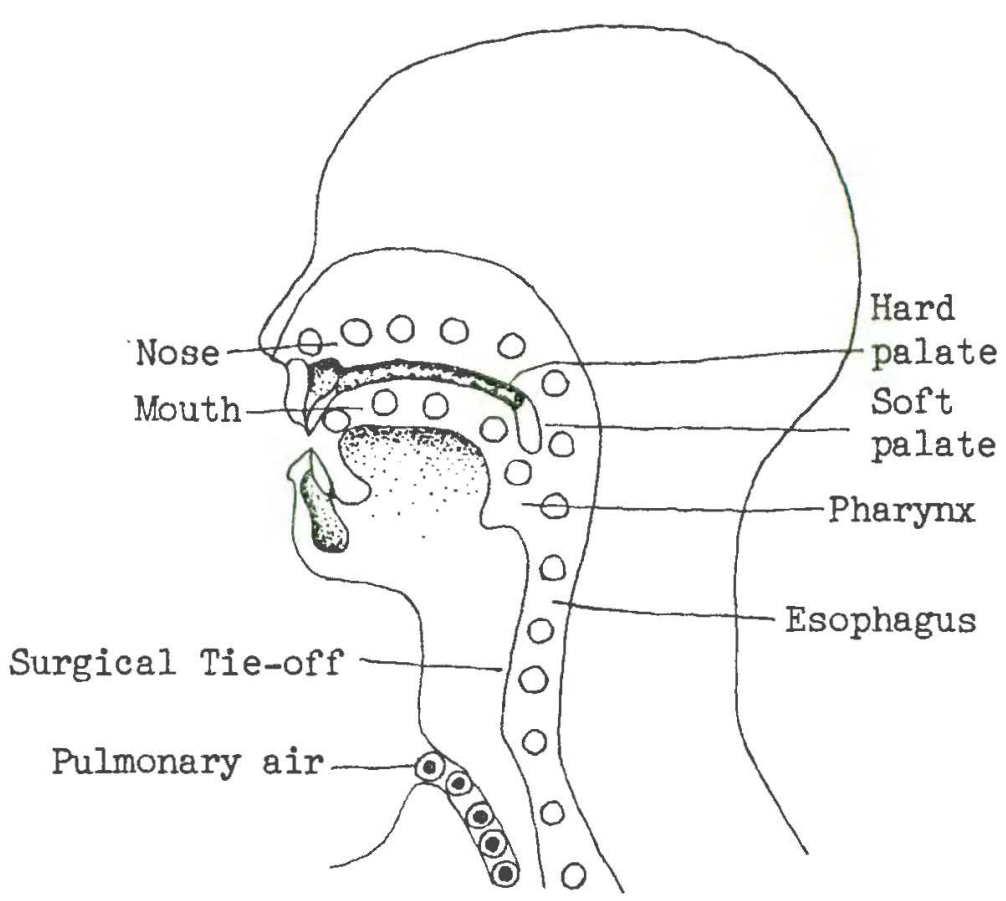

Phonic air 000 Pulmonary air $\bigcirc 0$

Figure 1. The head and neck before and after total laryngectomy (Snidecor, 1971 ). 
laryngectomees need the support of family and friends, need to be listened to and provided emotional relief and support.

Possibly the most deeply felt loss is that of the voice. Bisi and Conley (1965) have sumarized the importance of the voice, which has been taken from the laryngectomee, from a psychoanalytic view.

In evaluating the problem of rehabilitation of a laryngectomized patient, it must be pointed out that he has suddenly been deprived of an organ which since early childhood has served him for a number of important psychologic functions. These include: 1) a means of communication with other human beings, starting with the relationship in infancy with his parents, even before the development of speech, by using different sounds; 2) the expression of emotions; 3) the mastery of innumerable situations in the external world; 4) the means of active defense through attacking the adversary with words or screams, or passively, by pleading for help and mercy; 5) a means of reassurance against fear; 6) a source of gratification, especially in those who have invested libido narcissistically in their own voice; and 7) a way of carrying out sublimation. The voice is one of the most important and central facets of a person's identity.

Alaryngeal speech can be learned by the majority of laryngectomees (Lauder, 1969) and has been studied extensively in the literature. Studies conducted previously on intelligibility, speech acceptability, and the identification of the speaker from voice samples (speaker sex recognition) generally have been confined to studying one or two types of alaryngeal speech, e.g., Hyman (1955) compared voice acceptability of esophageal and artificial larynx voices, and Hoops and Noll (1971) studied the acceptability of esophageal voices. Laryngectomees, speech clinicians and physicians need to be provided with information which will assist in the selection of the most appropriate type of alaryngeal speech for each individual. Social acceptability is one criterion which may be an important consideration. This study, therefore, compared Asai, esophageal and artificial larynx speech on the parameter of social 
acceptability.

STATEMENT OF PURPOSE

The purpose of this investigation was to determine which method of alaryngeal speech is most socially acceptable to naive listeners. Specifically, this study proposed to determine how naive college age listeners rate the parameter of relative social acceptability from tape-recorded samples of three modes of alaryngeal speech: artificial larynx, esophageal, and Asai.

Answers to the following questions were sought:

1. Which type of alaryngeal speech is most socially acceptable to the naive listener?

2. What is the rank order of social acceptability of the three types of alaryngeal speech as rated by naive judges?

3. Do naive judges rate female and male alaryngeal voices similarly?

4. Do male and female judges rate alaryngeal voices in the same manner? 
CHAPTER II

REVIEW OF THE LITERATURE

In reviewing the literature on the social acceptability of alaryngeal speech, it is pertinent to understand how the three modes under discussion, i.e., esophageal, Asai, and artificial larynx speech, are learned and produced. The personal characteristics which aid and hinder the acquisition of alaryngeal speech will be considered. Intelligibility, social acceptability, professional bias, and speaker sex recognition studies will be reviewed as well.

\section{Methods of Alaryngeal Speech}

Esophageal Speech

Esophageal speech is used by 64 percent of laryngectomees and is generally preferred by speech pathologists over the use of the artificial larynx (Lauder, 1969 and 1970; Hartman and Scott, 1974). Esophageal speech utilizes a pseudoglottis, located near the top of the esophagus, in creating and maintaining the vibration necessary for speech (Warner, 1971). Shearer (1968) described the mechanics of esophageal speech in the following manner:

The new source of phonation is located between the hyoid bone and the inferior constrictor muscle. Vibration is caused by swallowed air being forced into the upper part of the esophagus (or lower part of the pharynx) and rapidly expelled. As the air is expelled a noise results in much the same way as it does in a toy balloon which has been inflated and released. This esophageal speech sounds harsh and raspy at first, but soon smooths out as the speaker gains 
better control and adds some nasal resonance.

The laryngectomee who chooses esophageal speech must learn to take in and expel air from the esophagus for speech. Warner (1971) stated the fundamental act in learning esophageal voice is the intake and expulsion of air from the esophagus in a controlled manner coordinated with the act of speaking. She described three established methods of air intake used by esophageal speakers:

Inhalation: Air is drawn into the oesophagus by rapid downward movement of the diaphragm and then expelled in a prolonged and controlled manner by the diaphragm rising slowly. A narrowing of the oesophagus from below upwards accompanies this, which may indicate the presence of antiperistalic movement.

Injection: Air can be injected into the oesophagus by the tongue and related oral structures. Air is pumped into the top of the oesophagus by rapid movement of the tongue. These movements resemble a swallowing pattern.

Plosive injection: Air is injected into the oesophagus in association with the production of the voiceless plosive consonants $(p)(t)(k)$.

According to Perkins (1971) these methods are most often used in combination, i.e., they are not used exclusively of each other and each individual speaker develops his own pattern of combination.

Characteristics of esophageal speech have been described in the literature. According to Perkins (1971), esophageal speech is normally described as hoarse. Snidecor (1971) reported the average esophageal speaker talks at a rate of 85 to 120 words per minute which is judged by the listener as slow. He uses a combination of injection methods and is able to speak three to four syllables per charge of air which is sufficient if air intake is rapid. Loudness level is reduced, but is sufficient to be heard in a group of twenty-five people in quiet conditions. Spectographic analysis has revealed more noise components than occur in 
the normal voice. Pitch is an octave lower than normal for males and two octaves for females, but pitch variability is not reduced. According to Diedrich and Youngstrom (1966):

Superior esophageal speakers average about 52 to 82 cps and a normal range can be expected. The esophageal speaker may not sound like he has a normal range in pitch because the frequency of the vibration is less than $100 \mathrm{cps}$ and the psychoacoustic perception of low pitch is one of monotone.

Esophageal speech may be considered more advantageous relative to Asai and artificial larynx speech from the standpoint that the individual is not required to use an instrument or restrict the use of one of his hands while speaking.

\section{Artificial Larynx}

A second type of alaryngeal speech is the use of the artificial larynx. Perkins (1971) divides artificial larynges into two basic categories: pneumatic and electronic. Pneumatic devices, according to Webster's New World Dictionary, are "filled with or worked by compressed air." Tokyo artificial larynges are an example of pneumatic devices. These depend upon breath pressure to activate a vibrating mechanism within an intraoral tube as the air passes from the stoma to the mouth, thus feeding the vibrating air directly into the mouth where it can be resonated and modified into speech (Boone, 1971; Goode, 1975).

The second type, electronic devices, generate sound electronically. This vibration is transmitted to the human resonating cavities by placement of the instrument on the neck. The sound is then modulated by the resonating cavities and the articulators. Lueders (1956) provided a description which is characteristic of the way electronic larynges operate:

This [electrolarynx] is an electronic instrument, basically a 
cylinder 4 inches in length and 1 inch in diameter, powered by a small battery. Its head, when held against the throat, produces vibrations which emerge from the mouth as sound. The patient's tongue, lips, and cheeks form the words as in normal speech. The voice produced with this instrument is monotone, but the speech is intelligible. Ambient noise from the instrument is annoying and should be lessened with adequate engineering effort. Results when it is used over the telephone are very satisfactory, for the reason that ambient noise is not transmitted. Volume is adequate under all circumstances.

Successful speech with an artificial larynx requires practice; it is not immediate (Western Electric Co., 1964). Perkins (1971) stated that possibly the most universal problem in successfully using an artificial larynx is learning to operate the "on and off" switch in synchrony with speech. The instrument should be generating tone for vowels and voiced consonants but not for voiceless consonants. Similarly, it must be turned off at the completion of a phrase or a droning noise is heard (Western Electric Co., 1964). The artificial larynx user must also learn to impound and use buccal air for plosives and fricatives to produce the necessary air flow and he must learn to coordinate this activity with the use of the artificial larynx (Perkins, 1971; Western Electric Co., 1964). According to Lueders (1956), speech with an artificial larynx is intelligible, characterized by monotone pitch and adequate volume. The quality of the voice is mechanical. According to Perkins (1971), "reasonable normal speaking rates" up to 150 words per minute can be obtained with normal phrasing achieved through practice.

Much controversy has centered around the use of the artificial larynx. Lauder (1970) reported that esophageal speech is preferred by the majority of speech pathologists over the artificial larynx. A number of objections to the use of the artificial larynx include: 1) the mechanical sound produced is unnatural, 2) the patient becomes 
dependent on the instrument so that it becomes a "crutch" thus interfering with the development of esophageal speech, and 3) the artificial larynx reportedly produces less intelligible speech than esophageal speech. Opponents, therefore, feel that an individual should not be supplied an artificial larynx until he has tried to learn esophageal voice (Lauder, 1968 and 1970).

Lueders (1956), however, emphasized that speech is a most important social function and disagreed with the above cited rationale. He stated it is of psychological importance to restore communicative ability as soon as possible as enforced silence while learning esophageal speech can result in resentment and frustration which in turn inhibits the acquisition of esophageal speech. Hence, he recommended an artificial larynx should be supplied to fill the immediate need to communicate. Lauder (1970) stressed the importance of supplying a laryngectomee with an artificial larynx for reasons of safety and peace of mind.

Proponents of the artificial larynx state that 1) it keeps communication alive; 2) it is economically beneficial; 3) it keeps morale high and relieves tensions, frustrations and anxieties which results in a favorable climate to learn esophageal speech; 4) early use of the artificial larynx, if properly taught, can increase the articulatory skills needed in esophageal speech; 5) it enables the production of intelligible speech; and 6) it can be provided immediately after the operation as a means of communication.

Diedrich, a speech pathologist interviewed by Lauder (1968), stated that a speech pathologist should offer the laryngectomee a choice and should then not feel badly if the patient chooses to use artifical 
Iarynx speech. Instead, Diedrich stated, the speech clinician should feel rewarded that he has provided a means of communication which the patient has chosen to use. According to Hartman and Scott (1974), "if an electronic larynx will fulfill the patient's psychological, vocational and communicative needs, it should be recommended to him."

\section{Asai Speech}

The third method of alaryngęal speech, Asai speech, is the result of a relatively new surgical procedure designed for the purpose of rehabilitation of the laryngectomized patient. The procedure allows the laryngectomized patient to use expired, pulmonary airflow for a more normal speech pattern. The operation was developed by Dr. Ryozo Asai in Japan, and was introduced to this country by Alden Miller. According to Snidecor (1971):

In this three-stage operation, a demal tube is formed which leads into the top of the tracheal stoma. Extending from this point upward the tube follows the midline of the neck and turns inward directly below the base of the tongue and ends in the hypopharynx. At elther the point of turning or opening into the pharynx, the tube vibrates much as does the top of the esophagus in esophageal speech. To generate a power source, a finger or thumb is placed over the tracheal stoma and air is forced upward to vibrate the neoglottis.

The surgical procedure for Asai speech is not the same as for a standard laryngectomy and the mechanism for phonation is altered in a different manner (Figure 2). Miller (1971) clearly explained the operative technique as follows:

The technique consists of three stages or operations. The first stage is employed at the end of an ordinary wide-field laryngectomy. After the removal of the larynx, the open end of the trachea is sutured to the skin opening of the midline of the neck in the usual fashion. When using the usual midline vertical skin incision for the laryngectomy, the open end of the trachea 


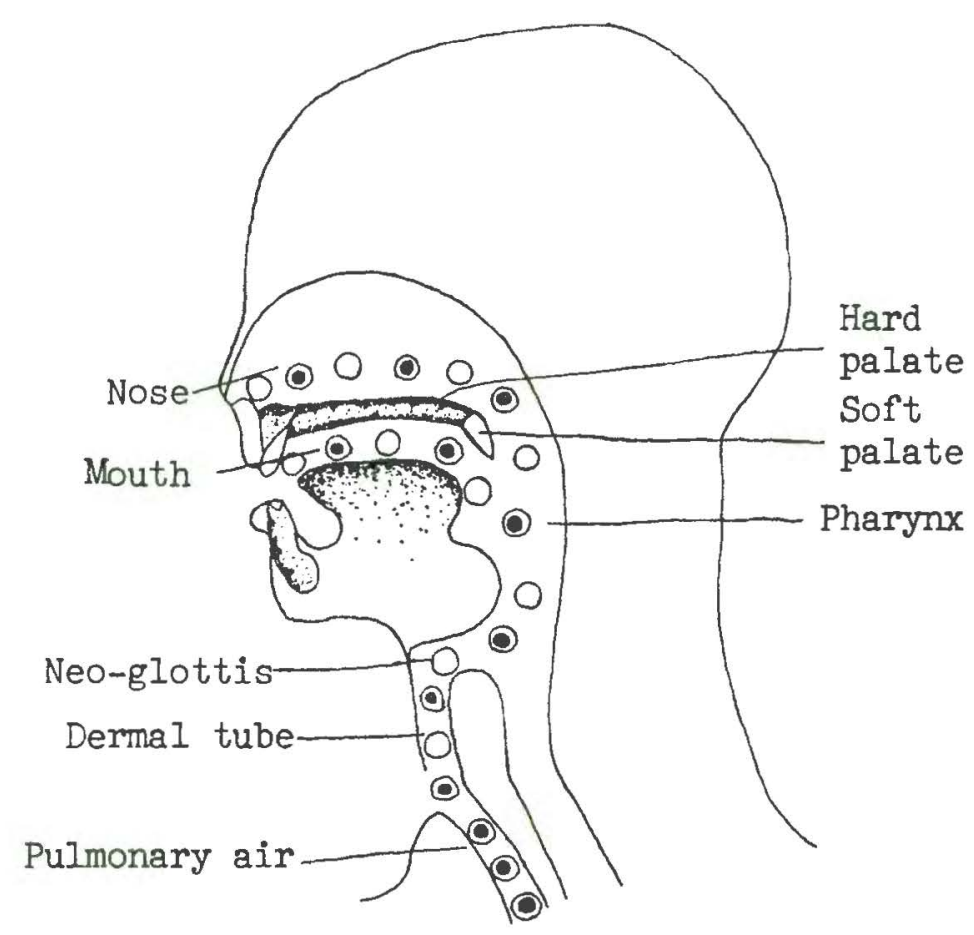

Phonic air 000

Pulmonary air $\bigcirc \bigcirc 0$

Figure 2. The head and neck after Asai surgery (Snidecor, 1971). 
is placed a centimeter or two higher than that usually done. A second, permanent tracheal stoma is then made through the fourth or fifth tracheal ring with two centimeters of skin between it and the upper opening. This latter will be the patient's permanent opening for breathing for the remainder of his life. The stoma made above it becomes the lower opening of the final dermal tube into the pharynx. This completes the first stage of the technique.

The second stage consists in making, a month or so later, a fistula into the pharynx, suturing mucosal edges to skin edges. This fistula should enter the pharynx just under the overhang of the bulging posteriorly of the base of the tongue. If the anterior part of the floor of the valleculae has been left, the fistula should enter beneath this ledge. The skin incision for this fistula is made in the area of the removed hyoid bone. The dissection inward is done in a downward or caudal direction so that the pharyngeal opening is at a lower level than the skin opening. The patient now has three stomae in a vertical line. The uppermost will become the upper end of the dermal tube.

The third and final stage, performed a month or so later, forms and buries the dermal tube. This tube is formed by making vertical skin incisions $1.3 \mathrm{~cm}$. on each side of the midline of the anterior neck and curving these incisions around and above the pharyngeal stoma, and around and below the upper tracheal stoma for the same distance. This produces an island of skin with these stomae at its vertical extremities. The cut edges of this island of skin are then approximated and sutured vertically in the midline with interrupted subcutaneous sutures over plastic tubing. Thus is formed a dermal tube connecting the upper end of the trachea with the pharynx. The remaining skin edges are then closed vertically in the midline over the dermal tube, burying it. Usually only slight undercutting of the edges is necessary in order to make this closure without tension. Unless the plastic tubing, to be removed after four or five days, is too tight a fit, the patient will be able to speak at once.

Putney and Bagley (1970) reported on a two-stage Asai technique which yields equivalent results while requiring one less surgery, thus reducing the time required for convalescence and speechlessness.

Speech characteristics of Asai speech have been reported in the literature. According to Miller (1971), the majority of Asai speakers have good to excellent voices which are superior to esophageal voices. They are reported to be much more normal sounding and to improve with practice. Asai speakers use average sentence length with normal pauses 
for breathing. Perkins (1971) reported that Asai speakers can talk with inflection and have a wider range of pitch and tone than do esophageal speakers. Their speaking rate can be normal and their pitch and loudness (volume) levels approach normal. Curry, et al. (1973), found Asai speech to have a higher fundamental frequency than esophageal but still lower than the normal male pitch. Asai speakers, however, tend to waste more air than esophageal speakers and, therefore, have a breathy quality to their voices (Perkins, 1971). Spectographic analysis reveals more aperiodic intervals in Asai speech than in esophageal speech (Curry, et al., 1973).

There are drawbacks to the Asai technique as well as advantages (Miller, 1971; Perkins, 1971; Putney and Bagley, 1970). The technique cannot be used with those who have undergone radiation treatment. Those who do choose this technique must undergo two or three operations instead of one. When talking, it is necessary for the Asai speaker to cover the tracheostoma with one finger to force the air through the dermal tube, which can present a problem to those who require the use of both hands. There is a tendency to aspirate fluid and food, but this can be controlled by exerting pressure on the skin over the upper end of the dermal tube while swallowing saliva or liquid food. Again, this requires the use of a hand. Putney and Bagley (1970) reported that occasionally necrosis (localized death of living tissue) of the skin between the tracheal openings develops. Miller (1971) and Putney and Bagley (1970) reported there is a mild problem with the growth of hair within the dermal tube.

According to Miller (1971), it is possible in some instances to 
perform a conversion from standard laryngectomy to Asai. He reported doing five such operations. This is offered only to those laryngectomees who have not been able to master esophageal speech and who do not want to use artificial larynx speech.

\section{Characteristics Related to Learning Alaryngeal Speech}

Although most speech pathologists encourage laryngectomees to learn esophageal speech, not all are able or choose to do so. Lauder (1969) reported 79 percent learn to speak by some method; 64 percent use esophageal speech exclusively; 10 percent use an artificial larynx exclusively; 5 percent use a combination of esophageal and artificial larynx speech; and 12 percent never learn to speak again. The other 9 percent surveyed did not report which method they used or fell into miscellaneous classification. To date, Asai speech has not been included in these statistics because it is such a new technique.

Gilchrist (1973) analyzed a number of factors to determine their connection to successful esophageal speech. He found lack of motivation to be the principle factor relating to the failure of learning esophageal speech. No relationship was found between successful esophageal speech and age, nature of surgery, number of speech sessions attended, radiotherapy, or the presence of a pharyngeal bar (at the base of the tongue near where the epiglottis was and found to be present in 60 percent of the people in his study). He did find women to be less successful, possibly because they find the "low course tones" embarrassing and/ or distasteful.

Martin (1963) reported: 
Esophageal speech, even if indifferent or poor quality, is indisputably the most convenient and therefore a desirable goal, but it is by no means essential to a happy and productive Iffe. It is unattainable by many patients, regardless of persistence.

Warner (1971) reported on a number of factors which may hamper the acquisition of esophageal speech: chronic bronchitis, hearing loss, blindness (because of the use of vision in early instruction), old age, frailty, lack of motivation, temperamental differences (tension), anxiety or depression, poor preoperative speech skills, distaste for the sound produced, and extensive radiotherapy.

Damsté (1956) found those laryngectomees who learn esophageal speech to have several characteristics in common: a strong desire to learn, sufficient intelligence, sufficient physical strength, especially in connection with respiration, and anatomical damage which is not too extensive. Interestingly, Shames (1963), reported on characteristics which were found to be common among successful artificial larynx and esophageal speakers: they are younger, are more educated, have less surgical involvement, and receive speech intervention soon after surgery.

Intelligibility and Social Acceptability Studies

According to Hartman and Scott (1974), "Since communication involves receiving speech as well as producing it, the adequacy of speech must be determined, in part at least, in the ears of the listener." This changing relationship between the speaker and listener is one reason the literature is inconclusive as to which type of alaryngeal speech is most intelligible or socially acceptable. The studies conducted in 
these areas vary in the types of alaryngeal speakers used (some have looked at only one mode while others have compared two or more modes of alaryngeal speech) and in the degree of sophistication of the judges in the area of speech pathology.

Hyman (1955) found audio-recordings of reed-type artificial larynx voices were preferred to esophageal voices by college students who were instructed to "choose the voice you would prefer to listen to." No significant difference in measure of intelligibility between the two groups was revealed. The subjects in both groups of alaryngeal speakers had been judged "good or effective" speakers.

Bennett and Weinberg (1973), however, found esophageal speech preferred to reed-type artificial larynx speech. They selected "superior" speakers representing four types of alaryngeal speech and normal speech. They found naive judges rated these voices in the following order of social acceptability: 1) normal speakers, 2) Tokyo artificial larynx speaker, 3) esophageal speakers, 4) Western Electric reed speakers, and 5) Bell Electro-larynx speakers.

Shipp (1967) related the measurement of certain phonatory variables in the speech of alaryngeal speakers, esophageal and pharyngeal, to measures of social acceptability as rated by naive listeners. The results showed acceptable ratings to be associated with a higher fundamental frequency, more rapid rate of speaking and little perception of respiratory noise. It was apparent that as the voices more closely approached normal, the higher the rating of acceptability.

Hartman and Scott (1974) observed and analyzed nonverbal and verbal responses of naive subjects to artificial larynx speech. Their results 
revealed that on only three of sixteen behaviors anslyzed were there significant differences in the patterns of responses between naive listeners who were exposed to normal speech and those who were exposed to artificial larynx speech. In response to artificial larynx speech, the naive listeners tended to stare more, to talk louder, or to talk slower. Hartman and Scott offered explanations to the variations in patterns of response. They hypothesized the naive listeners probably stared more because they were curious and/or they associated the artificial larynx speech with other problems (hearing loss) and therefore talked louder. The slower rate used was probably a result of a combination of these two factors. On the basis of the data collected by Hartman and Scott, it was concluded the potential adverse reactions associated with the use of the artificial larynx are minimal reactions which can be coped with and therefore need not interfere with communication. They concluded listener reaction should not be used as an argument against the use of the artificial larynx.

One aspect of social acceptability, speaker sex recognition, was studied by Weinberg and Bennett (1971), who conducted a study to determine if naive listeners reliably and accurately identify the sex of esophageal speakers from tape recorded volce samples. The results showed naive listeners can identify the sex of esophageal speakers from tape-recorded speech samples. When errors did occur, they were most frequently in the direction of female voices being identified as male voices. While males were rarely identified as female, approximately 25 percent of females seemed to exhibit a masculine voice. Having reviewed these studies on social acceptability and intelli- 
gibility of esophageal and artificial larynx speech, it is now of interest to look at the results of studies which indicate that listener sophistication plays an important role in the judgements of alaryngeal speech.

Hoops and Noll (1971) found the degree of sophistication in the area of speech pathology played an important role in the evaluation of esophageal speech. The results indicated individuals with experience in speech pathology tend to give poorer rating to esophageal speakers than do inexperienced listeners.

McCroskey and Muligan (1963), when comparing the relative intelligibility of esophageal and artificial larynx speech, demonstrated that experienced speech clinicians and graduate students in speech pathology rate the esophageal speakers higher in intelligibility while the naive listeners rated the artificial larynx speakers higher in intelligibility. Because the majority of speech pathologists prefer the use of esophageal speech over the use of. the artificial larynx, McCroskey and Mulligan indicated their ratings may be a reflection of a professional bias against the use of the artificial larynx.

Lauder (1968) sumnarized a series of studies by listing five characteristics of good esophageal speech. Although these characteristics are a summary of adequate esophageal speech characteristics, they possibly can be used to judge and compare the adequacy and social acceptability of all the modes of alaryngeal speech. The characteristics listed by Lauder are:

1. Sufficient volume to be comfortably heard by a listener with normal hearing at a reasonable distance in fairly quiet surroundings. 
2. Intelligibility supported by clarity of articulation, expressiveness, pitch variation, phrasing, and adequate visual cues.

3. Phonation produced with breath control resulting in a smooth speech flow, naturalness of expression, and avoidance of stoma blast.

4. Reasonable speech rate of at least 80 to 100 words per minute.

5. Few distracting speech mannerisms, facial grimaces, and inappropriate body movements during phonation.

\section{Summary}

Review of the literature has indicated that each of the three methods of alaryngeal speech under discussion, esophageal, artificial larynx, and Asai speech, may satisfy the communicative needs of individual alaryngeal speakers. The artificial larynx provides for voice almost immediately after a laryngectomy, but is mechanical sounding and requires an instrument and the use of one hand for voice. Asai speech requires additional surgery, but voice is available almost imnediately after the final surgery. The voice produced closely approximates normal, but is more breathy; again the use of one hand is required for voice, this time to force air through the dermal tube which is the source of phonation. Esophageal speech, preferred by the majority of speech pathologists, is rough-sounding and requires several months of practice to perfect. It does not require the use of an instrument or a hand.

Social acceptability involves a relationship between the speaker and the listener. What is acceptable to one listener may not be to another. There appears to be a difference in the way naive and sophisticated judges evaluate various types of alaryngeal speech. Combining the results of the studies conducted by Bennett and Weinberg (1973), Hyman 
(1955) and McCroskey and Mulligan (1936), it may be postulated that the order of social acceptability may be: 1) Tokyo artificial larynx speech, 2) reed-type artificial larynx speech and/or esophageal speech, and 3) electronic larynx speech. Although there have been several studies which have compared the social acceptability of esophageal speech and artificial larynx speech, there has been little comparison with Asai speech. It is, therefore, difficult to hypothesize the relative position of Asai speech as compared to the other types of alaryngeal speech. Additional research is needed in this area. 
CHAPTER III

METHODS AND PROCEDURES

METHODS

General Plan of Study

Twelve alaryngeal speakers were tape recorded reading the first paragraph of the Rainbow Passage (Appendix A) from which the second sentence from each reading was extracted and arranged in three sections on an audio-tape which was presented to judges. Initially, the voices were arranged and presented in random order to acquaint the judges with the range of voices to be judged. In the second presentation the voices were placed in a different random order which the judges rated on the parameter of relative social acceptability using a seven-point rating scale. After rating each voice individually, the judges listened to triads (groups of three) of voices and rank ordered the voices within each triad in order of social acceptability. Twenty-seven triads were composed of male voices and six of female voices. Each triad contained a member from each alaryngeal speech group with the voices within each triad arranged in random order. The results were analyzed to determine if any significant differences exist in the social acceptability of esophageal, artificial larynx, and Asai speech.

$\underline{\text { Subjects }}$

The subjects for this study were twelve alaryngeal speakers: four Asai, four artificial larynx, and four esophageal speakers. Each 
alaryngeal group was represented by one female and three male speakers. Each speaker was rated as a "good" or "effective" speaker by his physician, a speech pathologist, or an experienced alaryngeal speaker with a wide exposure to a variety of alaryngeal speakers. Each subject reported using the method of alaryngeal speech he was representing as his main method of communication, e.g., the esophageal speakers use esophageal speech for communicative purposes.

Judges

The judges for this study were ten college students, five male and five female, between the ages of 18 and 29 who reported no formal contact with alaryngeal speech and who also reported normal hearing acuity. This information was determined by the questionnaire shown in Appendix B.

Instrumentation

The speech samples were recorded on Ampex 651 tape using a Uher tape recorder, model number 4000, and accompanying microphone. The portability of this machine was an asset because of the distances traveled in the collection of the voice samples. Two Sony 105 tape recorders were used to produce the judging tape and to present the tape to the judges.

The dubbing process involved a two-step procedure. The first step involved the extraction of the second sentence from each individual reading from the master (original) tapes and the placement of the samples onto a second generation tape. Using this second generation tape and the two Sony tape recorders, the voices were arranged in the order 
necessary for presentation to the judges. The arrangement of the voices is discussed in the next section and is outline in Appendix C.

\section{PROCEDURES}

$\underline{\text { Recording and Presentation Procedures }}$

The speech samples were collected in quiet rooms in the subjects' homes and places of business by two Master degree candidates in Speech Pathology and Audiology. One investigator collected all Asai speech samples, one artificial larynx sample and one esophageal speech sample. The other investigator collected one esophageal and two artificial larynx speech samples. The remainder of the speech samples were collected jointly by the two investigators.

Each subject read the first paragraph of the Rainbow Passage (Appendix A) into a microphone held six to eight inches in front of the mouth at the level of the chin. The speech samples were recorded and presented to the judges at a speed of 3 and $3 / 4$ inches per second.

The second sentence from each sample was extracted and included in three sections on a tape which later was presented to the judges. In the first section, using a random numbers table, the twelve voice samples were arranged in random order (Appendix C). This initial presentation was to acquaint the judges with the range of voices they would be rating in sections two and three. Section two consisted of fifteen voice samples with five-second intervals between each voice, to allow the judges time to rate each voice individually on a seven-point rating scale on the parameter of relative social acceptability. The twelve subjects' voices were arranged in random order followed by three random- 
ly selected voices, which were selected from the twelve and presented a second time to determine intrajudge reliability. Appendix C illustrates the exact order of presentation. The third section consisted of thirtythree different triads (groups of three individual voices). Each triad contained a member from each alaryngeal speech group, with the voices within each triad arranged in random order. Twenty-seven triads were composed of male voices and six of female voices. Each male speaker was paired at least once with every other male speaker. As there were only three female speakers and six triads in which they were presented, the order of presentation was varied each time. The exact order of presentation is illustrated in Appendix C. Each triad was presented twice, the first time to acquaint the judges with the voices in the triad and the second time to allow them to rank order the voices within the triad on the parameter of social acceptability. Five-second intervals were placed between each triad.

\section{Rating Procedures}

Two rating measures were used: 1) a seven-point rating scale, and 2) a rank ordering of the voices within the triads (Appendix D). The seven-point rating scale was used in conjunction with section two of the audio-tape and was used to rate the relative social acceptability of individual voices in relation to the other voices. The second rating procedure, the rank ordering of voices, involved ranking three voices within each triad in order of social acceptability, with "l" representing the most acceptable voice in the group, " 2 " the next, and " 3 " representing the least socially acceptable voice in the triad. The actual instructions to the judges may be found in Appendix E. 


\section{Data Analysis}

The rating scale data was analyzed initially to verify intrajudge and interjudge reliability using Pearson product-moment correlation $(r)$. A one-way analysis of variance was conducted on the total sample (male and female speakers) to determine if any statistically significant differences exist in social acceptability of Asai, artificial larynx, and esophageal speech. Likewise, a one-way analysis of variance was conducted using only male speakers. t tests for dependent means were used to determine statistical significance between alaryngeal groups using male and female speakers, and male speakers alone. To determine whether speaker sex or judge sex influenced the rating scores obtained and assigned, $t$ tests were conducted. A $t$ test for dependent means was used to determine whether judge sex was a variable in the ratings assigned to the alaryngeal speakers. A $\underline{t}$ test for independent means was used to determine if speaker sex was a variable in the ratings obtained.

Interjudge reliability on the ranking data was determined using a Kendall Coefficient of Concordance (W) (Siegel, 1956). A Kruskal-Wallis one-way analysis of variance (H) (Siegel, 1956) was conducted to determine if a statistically significant difference exists in the ranking of the three modes of alaryngeal speech. 
CHAPTER IV

\section{RESULTS AND DISCUSSION}

\section{$\underline{\text { RESULTS }}$}

The purpose of this investigation was to determine which method of alaryngeal speech is most socially acceptable to naive listeners. Specifically, this study proposed to determine how naive college age listeners rate the parameter of relative social acceptability from tape recorded samples of three modes of alaryngeal speech: artificial larynx, esophageal, and Asai.

To determine intrajudge reliability, the Pearson product-moment correlation ( $r$ ) was used. The rating judgements of each of the three voices which were rated twice on the seven-point rating scale were correlated across all ten judges. As seen in Table I, statistically significant intrajudge reliability was not found when comparing the first and second ratings of the artificial larynx voice with a resulting $\underline{r}$ of -.13. Statistically significant intrajudge reliability was obtained on both the Asai and the esophageal voices with $\underline{r}^{\prime} s$ of .63 and .58 , respectively.

The Pearson product-moment correlation $(r)$ was used to determine interjudge reliability on the rating scale data. Six judges were randomly selected using a table of random numbers and were then paired. Three correlations were computed using the social acceptability ratings from the seven-point rating scale, for the twelve voice samples. The 
TABLE I

RATING SCALE INTRAJUDGE RELIABILITY

\begin{tabular}{lcccr}
\hline Voice Replication & $\mathrm{r}$ & $\underline{\mathrm{t}}$ & $\mathrm{p}$ & $\mathrm{df}$ \\
\hline Artificial larynx voice & -.13 & .3708 & - & 8 \\
Asai voice & .63 & 2.2944 & .05 & 8 \\
Esophageal voice & .58 & 2.0137 & .05 & 8 \\
\hline
\end{tabular}


last three samples from the rating scale were not used in these correlations as these were replications included for determining intrajudge reliability. As seen in Table II, statistically significant interjudge reliability was found in all three correlations with a resulting mean $\underline{\mathrm{r}}$ of .72 .

TABLE II

RATING SCALE INTERJUDGE RELIABILITY

\begin{tabular}{lcccc}
\hline $\begin{array}{l}\text { Judge } \\
\text { Combinations }\end{array}$ & $\mathrm{r}$ & $\underline{\mathrm{t}}$ & $\mathrm{p}$ & $\mathrm{df}$ \\
\hline 8 and 10 & .51 & 1.8737 & .05 & 10 \\
3 and 9 & .89 & 6.1688 & .0005 & 10 \\
5 and 6 & .78 & 3.9392 & .0025 & 10 \\
Mean & .72 & 3.2788 & .005 & 10 \\
\hline
\end{tabular}

A one-way analysis of variance was conducted to determine if a difference existed in the ratings of the three methods of alaryngeal speech on the basis of the rating scale data. Because of the high interjudge reliability obtained previously, average scores for each speaker were used in the analysis rather than using individual judge ratings. Table III summarizes the findings. Analyses were conducted using both male and female speakers and using male speakers alone. An $\underline{F}$ distribution of .812 was found among the three groups when using male and female speakers, indicating no statistically significant difference in the ratings of the three methods of alaryngeal speech. However, when conducting a one-way analysis of variance on the male voices only, a significant $\underline{F}$ distribution of 14.63 was found indicating a statistically 
significant difference among the groups.

TABLE III

ONE WAY ANALYSIS OF VARIANCE OF RATING SCALE DATA

\begin{tabular}{llcll}
\hline \hline Source & $\bar{x}$ & SD & $\bar{F}$ & p \\
\hline $\begin{array}{l}\text { Male and female speakers } \\
\text { Artificial larynx }\end{array}$ & 2.82 & .98 & & \\
Asai & 3.39 & 1.05 & .812 & - \\
Esophageal & 5.22 & 1.76 & & \\
Male speakers & & & & \\
Artificial larynx & 2.34 & .30 & & .005 \\
Asai & 2.95 & .69 & 14.63 & \\
Esophageal & 6.08 & .50 & & \\
\hline
\end{tabular}

Two-tailed $\underline{t}$ tests for dependent means were conducted on the total sample (male and female voices) and on the male voices alone to determine whether statistically significant differences existed between pairs of alaryngeal groups, i.e., Asai versus esophageal, Asai versus artificial larynx, and esophageal versus artificial larynx. Although the one way analysis of variance conducted on the total sample indicated no statistically significant differences between groups, t tests were conducted because of differences noted in the mean scores obtained by the alaryngeal groups (Table III). As shown in Table IV, when comparing the total sample, a statistically significant $t$ value of 3.25 was found between Asai and artificial larynx groups, but not between esophageal and artificial larynx or between esophageal and Asai groups. The results additionally indicated the Asai speakers were rated higher than the 
artificial larynx group.

TABLE IV

INTERGROUP COMPARISONS OF SOCIAL ACCEPTABILITY

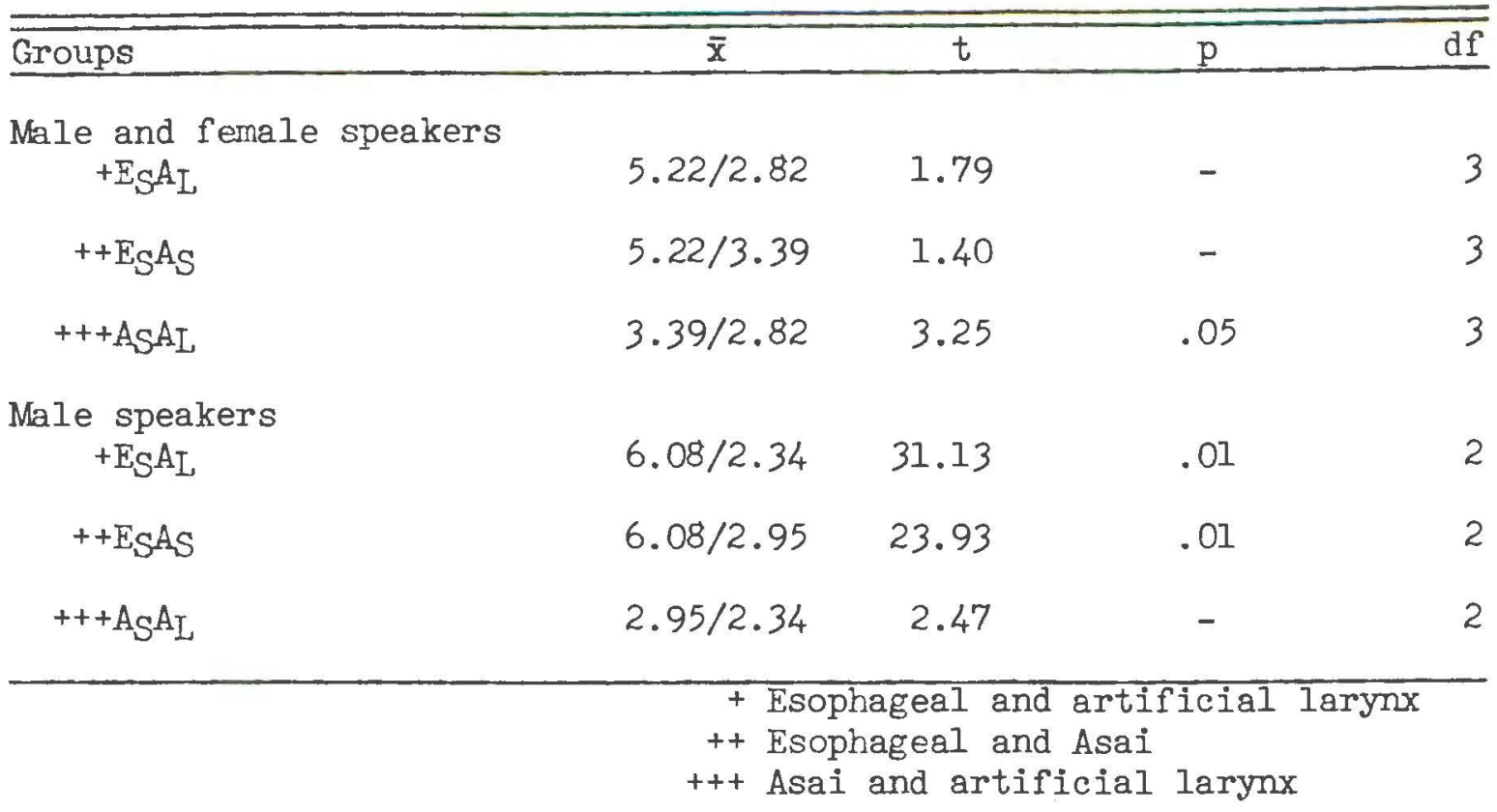

Because of the differences noted in the mean scores between male and female subjects within alaryngeal groups (Table $V$ ), two-tailed $\underline{t}$ tests for dependent means were conducted on the male sample alone. The results of the $t$ tests (Table IV) indicated statistically significant $t$ scores when comparing esophageal and artificial larynx speakers and when comparing esophageal and Asai speakers, with t scores of 31.13 and 23.93 respectively. A statistically significant $t$ was not found between artificial larynx males and Asai males. As shown in Table IV, the results of the $\underline{t}$ tests conducted on male speakers indicated male esophageal speakers were preferred over both male Asai and artificial larynx speakers. 
TABLE V

GROUP MEAN SCORES FROM RATING SCALE DATA

\begin{tabular}{lccc}
\hline Group & Male and Female & Male & Female \\
\hline Esophageal speakers & 5.22 & 6.08 & 2.65 \\
Artificial larynx speakers & 2.82 & 2.34 & 4.25 \\
Asai speakers & 3.39 & 2.95 & 4.72 \\
\hline
\end{tabular}

To determine whether subject sex had an influence on the rating scores, a two-tailed $\underline{t}$ test for independent means was conducted on the average scores of each subject by comparing male and female scores. A t value of .06 was obtained showing no statistical significance between subject sex and the value of the scores obtained (Table VI).

TABLE VI

INFLUENCE OF SUBJECT SEX ON SCORES OBTAINED

\begin{tabular}{cccccc}
\hline \hline Subject sex & $\bar{x}$ & SD & t & P & df \\
\hline Male & 3.79 & 1.79 & & & \\
Female & 3.87 & 1.08 & .06 & - & 10 \\
\hline
\end{tabular}

A $t$ test for dependent means was conducted to determine if the sex of the judges was a variable in the scores assigned to the subjects. As shown in Table VII, when correlating the average scores assigned by each judge, a $\underline{t}$ value of 1.20 was obtained revealing no significance related to judge sex and the scores assigned. 
TABLE VII

INFLUENCE OF JUDGE SEX ON SCORE ASSIGNED

\begin{tabular}{ccrccc}
\hline \hline Judge sex & $\overline{\mathbf{x}}$ & SD & t & p & df \\
\hline Male & 4.70 & 1.70 & & & \\
Female & 3.70 & .45 & 1.20 & - & 3 \\
\hline
\end{tabular}

Interjudge reliability of the ranking data was determined using a Kendall Coefficient of Concordance (W). Because each male voice was rated nine times and each female voice six times, three ratings of each male voice were discarded. The ratings discarded were the same for each judge and were determined using a random numbers table. A correction for tied ranks was performed. The resulting W was .786 . In order to determine significance of $\underline{W}$, chi square was calculated and found to be 86.46 , which is significant at .001 level, indicating consistency among judges in the ranking of the voices.

A Kruskal-Wallis One Way Analysis of Variance ( $H$ ) was conducted to determine if a significant difference in the ranking of the three modes of alaryngeal speech existed. An $\underline{H}$ of 9.014 was obtained which was found to be statistically significant at the .01 level indicating a significant difference in the rankings of the three modes of alaryngeal speech. The male speakers were ranked in the following order of social acceptability: 1) esophageal, 2) Asai, and 3) artificial larynx. The female speakers were ranked ordered as follows: 1) Asai and 2) esophageal and artificial $\operatorname{larynx}$. 
DISCUSSION

This investigation was designed to answer the following questions:

1. Which type of alaryngeal speech is most socially acceptable to the naive listener?

2. What is the rank order of social acceptability of the three types of alaryngeal speech as rated by naive judges?

3. Do naive judges rate female and male alaryngeal voices similarly?

4. Do male and female judges rate alaryngeal voices in the same manner?

In response to question four, do male and female judges rate alaryngeal voices in the same manner, the results of a $t$ test for dependent means, revealed the sex of the judges did not influence the rating scores assigned by the judges. Male and female judges rated the alaryngeal speakers in a like manner.

The third question, do naive judges rate female and male alaryngeal speakers similarly, was analyzed with a $\underline{t}$ test for independent means using the rating scale data. The resulting $\underline{t}$ score indicates that speaker sex is not a factor in the rating of voices. In other words, male and female alaryngeal speakers tended to be rated similarly; neither males nor females were rated higher than the other group of subjects. Although the judges were informed they would be listening to male voices 75 percent of the time, specific voices were not identified for the judges as being male or female. According to Weinberg and Bennet (1971), naive listeners generally are able to identify speaker sex of esophageal speakers from tape-recorded speech samples. From this research, it can be hypothesized the judges may have been able to identify 
female esophageal speakers from males; however, no conclusions can be drawn concerning the identification of the sex of Asai and artificial larynx speakers as no research was found which concerned speaker sex recognition of these alaryngeal groups.

Questions one and two, which type of alaryngeal speech is most acceptable to the naive listener and what is the rank order of social acceptability of the three types of alaryngeal speech as rated by naive judges, may be answered simultaneously. According to the one way analysis of variance conducted on the rating scale data of the male and female speakers combined, there is no statistically significant difference in the social acceptability of the three types of alaryngeal speech. However, the $\underline{t}$ tests conducted using male and female speakers resulted in a statistically significant difference between Asai and artificial larynx speech (with Asai speech being preferred) but not between any other combinations, i.e., artificial larynx and esophageal, or esophageal and Asai. Interestingly, the mean score of the esophageal group $(\bar{x}=5.22)$ was found to be higher than either of the means of the Asai $(\bar{x}=3.39)$ or artificial larynx $(\bar{x}=2.82)$ groups. Although this difference is not statistically significant, a trend for preference of esophageal speech is suggested.

When conducting a one way analysis of variance on the male speakers alone, a statistically significant difference was found in social acceptability with the order of acceptability being: 1) esophageal, 2) Asai, and 3) artificial larynx. t tests conducted comparing pairs of these alaryngeal groups yielded statistically significant differences between the esophageal and artificial larynx male voices (with esophageal voice 
preferred) and between the esophageal and Asai male voices (with esophageal voice preferred), but not between the artificial larynx and Asai groups.

The mean scores of the esophageal group (from the rating data) when considering male and female speakers together, and the statistically significant preference of esophageal speech when considering male speakers alone tend to identify esophageal speech as that method most socially acceptable to the naive listener.

When examining the ranking data, a difference in the rank ordering of male and female speakers is noted. The male speakers were ranked in the following order of social acceptability: 1) esophageal, 2) Asai, and 3) artificial larynx. This order is the same found in the rating data as indicated by the mean scores. The female speakers were ranked in the following order of social acceptability: 1) Asai, and 2) esophageal and artificial larynx (ranked equally). This order of social acceptability for females tends to be supported by the mean scores obtained from the rating scale data. Although these data were not statistically analyzed the Asai speaker received the highest mean rating ( $\bar{x}=4.72)$; the the artificial larynx speaker, the second highest mean rating $(\bar{x}=4.25)$; and the esophageal speaker, the lowest mean rating $(\bar{x}=2.65)$. It appears there is a difference in the way male and female speakers were ranked on the parameter of social acceptability.

One must be cautious, however, in drawing conclusions from this data, especially relative to the female voices as there was only one female subject representing each alaryngeal speech group. The rank order obtained possibly represents the order of social acceptability for those 
individual voices rather than for the alaryngeal groups they represented. Assuming the judges were able to identify the sex of the speakers, it is interesting to postulate the breathy, higher-pitched Asai voice might be more socially acceptable for females as opposed to the "harsher-sounding" esophageal or the more "mechanical-sounding" artificial larynx voices. It was also very difficult to control for speaker variability across groups and within groups. Although each speaker was rated "good" or "effective", variability existed in expertise of the use of the modes of alaryngeal speech which may have influenced the scores obtained.

The ranking data was in agreement with the rating scale data indicating esophageal speech is the most socially acceptable of the three modes of alaryngeal speech for male speakers. The same cannot be said for female speakers as the ranking data indicated Asai speech is the preferred mode for female speakers. No studies were found in the literature which have been conducted comparing these three modes of alaryngeal speech. These results do not support those of Hyman (1955) who found a preference of artificial larynx speakers to esophageal speakers. Hyman's study, however, used reed-type larynges; whereas, all of the speakers in this study used electronic larynges. Bennet and Weinberg (1973) found Tokyo artificial larynges to be more acceptable to listeners than either esophageal speech or electronic artificial larynges. Esophageal speech has been considered the most acceptable type of alaryngeal speech by the majority of speech pathologists (Hartman and Scott, 1974). The naive listeners in this study supported this view relative to male speakers. 
CHAPTER V

SUMMARY AND IMPLICATIONS

\section{SUMMARY}

As a result of the surgical removal of the larynx, the laryngectomee is no longer able to speak and must choose to learn a new method of oral communication if he wishes to communicate orally. Laryngectomees, speech clinicians and physicians need to be provided with information which will assist in the selection of the most appropriate type of alaryngeal speech for each individual. Social acceptability is one criterion which may be an important consideration. This study, therefore, compared three modes of alaryngeal speech: Asai, esophageal, and artificial larynx, on the parameter of social acceptability.

Specifically, this study proposed to determine which type of alaryngeal speech is most socially acceptable to a naive listening sample. Answers to the following questions were sought:

1. Which type of alaryngeal speech is most socially acceptable to the naive listener?

2. What is the rank order of social acceptability of the three types of alaryngeal speech as rated by naive judges?

3. Do naive judges rate female and male alaryngeal voices similarly?

4. Do male and female judges rate alaryngeal voices in the same manner?

The subjects for this study were twelve alaryngeal speakers: four Asai, four artificial larynx, and four esophageal speakers. Each 
alaryngeal group was represented by one female and three male speakers judged to be "good" or "effective" speakers.

The subjects were tape recorded while reading the first paragraph of the Rainbow Passage from which the second sentence from each voice sample was extracted and arranged in three sections on an audio-tape which was presented to judges. In the first section, the voices were arranged and presented in random order to acquaint the judges with the range of voices being judged. In the second section, the volces were presented in a different random order. The judges rated the voices in this presentation on the parameter of relative social acceptability using a seven-point rating scale. In the third section, the judges listened to triads (groups of three) of voices and rank ordered the voices within each triad in order of social acceptability. Each triad contained a member from each alaryngeal speech group, with the voices within each triad arranged in random order. Twenty-seven triads were composed of male voices and six of female voices. The results were analyzed to determine if any statistically significant differences exist in the speech social acceptability of esophageal, artificial larynx, and Asai speech.

The findings indicate sex of the judges did not influence the rating scores assigned to the voices. Male and female judges rated the alaryngeal speakers in a like manner, neither groups scoring the voices higher or lower than the other.

Analysis of the rating scale data revealed no statistically significant differences in the scores generally assigned male and female speakers. Neither male nor female speakers received higher ratings. 
According to the mean scores of the alaryngeal groups obtained from the rating scale data, esophageal speech was the preferred method of alaryngeal speech on the parameter of social acceptability. This was not a statistically significant preference when considering male and female speakers together but merely a trend. However, when considering the male speakers alone, a statistically slgnificant difference was found among the groups with the order of social acceptability being: 1) esophageal, 2) Asai, and 3) artificial larynx. The ranking data indicated male and female speakers are ranked in different orders of social acceptability. The female speakers were ranked as follows on the parameter of social acceptability: 1) Asai, and 2) esophageal and artificial larynx (ranked equal).

The size of the sample requires the results obtained to be viewed as trends. Replication of this study using a larger sample should be completed to confirm the results.

\section{IMPLICATIONS}

\section{Clinical}

The overall trends found in this study partially support the view held by many speech pathologists that esophageal speech is the preferred method of alaryngeal speech in that the male esophageal speakers tended to be rated higher than the male artificial larynx and Asai speakers. Therefore, laryngectomized men might continue to be encouraged to learn esophageal voice from the standpoint of social acceptability.

The finding that the female Asal speaker obtained higher ranking scores than the female esophageal or artificial larynx speakers may have 
clinical implications. Asai speech is breathier and has a higher fundamental frequency (Snidecor, 1975) than esophageal speech and therefore it may be particularly important for female laryngectomees to seriously consider using the Asai mode of alaryngeal speech.

\section{Research}

Replication of this study using a larger sample size and/or more controlled variability of the speakers within each alaryngeal group is urged. A larger sample investigation would confirm or reject the trends found in the present study and would be useful in the selection of the most acceptable type of alaryngeal speech for an individual speaker. Proficiency of the speakers may also influence judge rating and rankings of the three modes of alaryngeal speech. Results might also be more revealing if the sex of the speaker was identified for the judges prior to each rating. Sex identification was not done in this study and, consequently, it is impossible to determine if the sex of the speaker influenced the social acceptability of the voices.

Previous studies comparing esophageal and artificial larynx speech have not been consistent in the parameter studied or the type of artificial larynges used. It would be interesting to compare the relative social acceptability of esophageal, Asai, Tokyo artificial larynges, electronic artificial larynges and reed-type artificial larynges. It has been previously shown that reed-type artificial larynx speech is preferred by naive listeners to esophageal and electronic larynx speech. Asai speech has not been included in these studies and it would be interesting to do so.

Studies of the identification of speaker sex from tape recorded 
samples have been conducted using esophageal speakers. Similar studies might be conducted using Asai speakers, as well as electronic and reedtype artificial larynx speakers.

Certainly, more research in speech social acceptability needs to be conducted to aid laryngectomees in selecting a mode of alaryngeal speech. 


\section{SELECTED BIBLIOGRAPHY}

Bennett, Suzanne, and Weinberg, Bernd. Acceptability ratings of normal, esophageal, and artificial larynx speech. J. Speech Hearing Res., $16,608-615$ (1973).

Bisi, Ricardo H., M.D., and Conley, John J., M.D. Psychologic factors influencing vocal rehabilitation of the postlaryngectomy patient. Ann. Otol. Phinol. Laryng., 74 (4), 1073-1078 (1965).

Boone, Daniel R. The Voice and Voice Therapy. New Jersey: PrenticeHall, Ine. (1971).

Curry, E. Thayer, Ph.D., Snidecor, John C., Ph.D., and Issihiki, Nobuhiko, M.D. Fundamental frequency characteristics of Japanese Asai speakers. Laryngscope, 83 (1973).

Damsté, P.H., et al. Why are some patients unable to learn esophageal speech? Ann. Otol. Phinol. Laryng., 65(4), 998-1005 (1956).

Diedrich, William, Ph.D., and Youngstrom, Karl A., Ph.D., M.D. Alaryngeal Speech. Illinois: Charles C. Thomas (1966).

Gardner, Warren H., Ph.D. Adjustment problems of laryngectomized women. Arch. Otolaryng., 83, 31-42 (1966).

Gilchrist, A.G. Rehabilitation after laryngectomy. Acta otolaryng., $75(6) ; 511-518$ (1973).

Goode, Richard C., M.D. Artificial laryngeal devices in post-laryngectomy rehabilitation. Laryngoscope, 85(4), 677-689 (1975).

Hartman, David E., and Scott, Davis A., Ph.D. Overt responses of listeners to alaryngeal speech. Laryngoscope, 84(3), 410-416 (1974).

Hoops, H. Ray, and Noll, J. Douglas. The effects of listener sophistication on judgements of esophageal speech. J. Commun. Dis., 3, 250-260 (1971).

Hunt, R. Brooks, M.D. Rehabilitation of the laryngectomee. Laryngoscope, 74(3), 382-395 (1964).

Hyman, Melvin. An experimental study of artificial-larynx and esophageal speech. J. Speech Hearing Dis., 20(3), 291-299 (1955). 
Lauder, Edmund. The laryngectomee and the artificial larynx. J. Speech Hearing Dis., 33(2), 147-157 (1968).

- A laryngectomee's viewpoint on the intelligibility of esophageal speech.' J. Speech Hearing Dis., 34(4), 355-360 (1969).

- The laryngectomee and the artificial larynx--a second look. J. Speech Hearing Dis., 35(1), 62-65 (1970).

Lueders, Oscar W. Use of the electrolarynx in speech rehabilitation. Arch. Otolarying., 63, 133-134 (1956).

Martin, H. Rehabilitation of the laryngectomee. Cancer, 16, 834 (1963).

McCroskey, R. and Mulligan, M. The relative intelligibility of esophageal speech and artificial larynx speech. J. Speech Hearing Dis., 28, 37-41 (1963).

Miller, Alden H. Four years experience with the Asai technique for vocal rehabilitation for the laryngectomized patient. J. Laryng. Otol., 85(6), 567-576 (1971).

Negus, V.E. The Mechanism of the Larynx. London: William Heinmann, Itd. ( 1929 ).

Perkins, William H. Chapter 13: Disorders of phonation. Speech Pathology: an applied behavioral science. Saint Louis: The C.V. Mosby Co. (1971).

Putney, F. Johnson, M.D., and Bagley, Carter S., M.D. The two stage Asai technique of laryngectomy. Ann. Otol. Rhinol. Laryng., $79(6), 1057-1060$ (1970).

Shames, G.H., et al. Factors related to speech proficiency of the laryngectomized. J. Speech Hearing Dis., 28(3), 273-287 (1963).

Shearer, William M. Illustrated Speech Anatomy. Illinois: Charles C. Thomas (1968).

Shipp, Thomas. Frequency, duration, and perceptual measures in relation to judgements of alaryngeal speech acceptability. J.Speech Hearing Res., 10, 417-427 (1967).

Siegel, Sidney. Nonparametric Statistics for the Behavioral Sciences. New York: McGraw-Hill Book Co., Inc. (1956).

Snidecor, John C. Speech Rehabilitation of the Laryngectomized. Illinois: Charles C. Thomas (1968). 
Snidecor, John C. Chapter 22: Speech without a larynx. Handbook of Speech Pathology and Audiology, ed. Lee E. Travis, New York: Appleton-Century-Croft (1971).

- Some scientific foundations for voice restoration. 'Laryngoscope, 85(4) (1975).

Warner, Jennifer. Vocal rehabilitation following total laryngectomy. J. Laryn. Otol., 85(6), 577-582 (1971).

Weinberg, B., and Bennett, S. The study of talker sex recognition of esophageal voices. J. Speech Hearing Res., 14, 391-395 (1971).

Western Electric \#5 Type Electronic Artificial Larynx: Instruction Manual. \#1304 Issue \#2. Western Electric Company, Inc. by $\overline{B e l 1 ~ T e l e p h o n e ~ C o m p a n y ~(1964) . ~}$ 
APPENDIX A

THE RAINBOW PASSAGE

When the sunlight strikes raindrops in the air, they act like a prism and form a rainbow. The rainbow is a division of white light into many beautiful colors. These take the shape of a long round arch, with its path high above, and its two ends apparently beyond the horizon. There is, according to legend, a boiling pot of gold at one end. People look, but no one ever finds it. When a man looks for something beyond his reach, his friends say he is looking for the pot of gold at the end of the rainbow. 


\section{APPENDIX B}

\section{QUESTIONNAIRE USED IN THE SELECTION OF JUDGES}

NAME:

AGE:

SEX:

PHONE NUMBER:

WHAT IS THE EXTENT OF YOUR EXPOSURE TO ALARYNGEAL SPEAKERS? NONE

VERY LITTLE

( INFORMALIY, ONCE OR

TWICE)
FREQUENT

(FORMAI)

DO YOU HAVE NORMAL HEARING?

HAVE YOU EVER HAD A HISTORY OF HEARING LOSS OR CHRONIC EAR INFECTION? TIMES AVAILABLE: 
APPENDIX C

PRESENTATION ORDER OF VOICES SUPERIMPOSED ON SCORING FORM

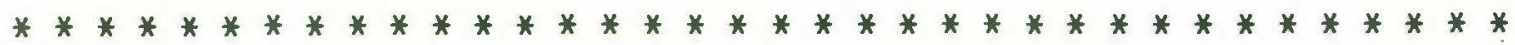
Coding:

$A=\operatorname{artificial~larynx~voices~}$

$B=$ Asai voices

$\mathrm{C}=$ esophageal voices

1, 2 and $3=$ individual male speakers within each alaryngeal group $4=$ female speaker within each alaryngeal group

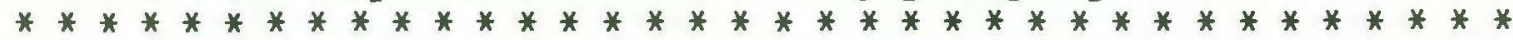

THE RELATIVE SOCIAL ACCEPTABILITY OF ALARYNGEAL SPEECH

JUDGE \#

AGE

SEX

SECTION ONE: LISTEN: NO SCORING

SECTION TWO:
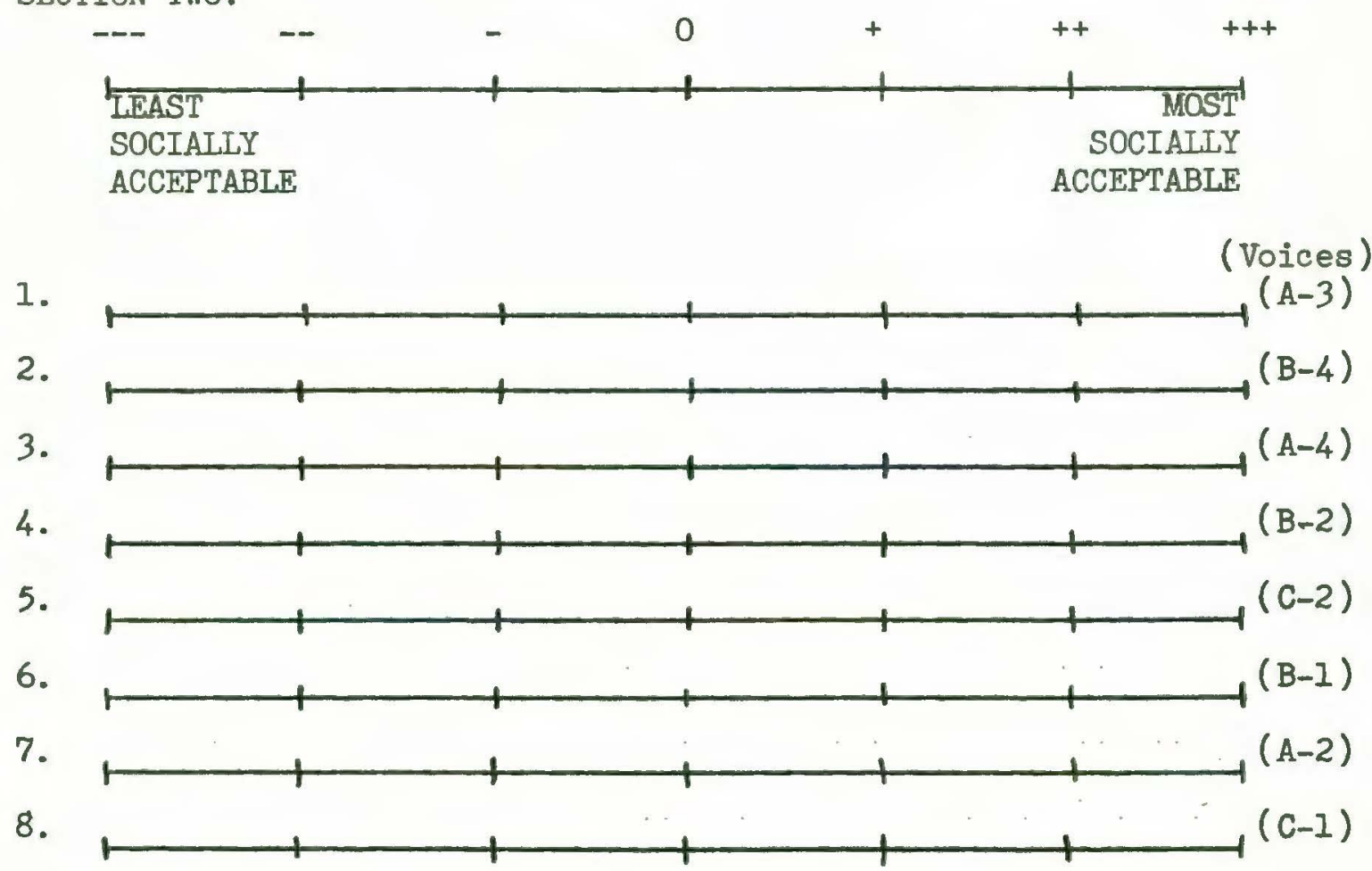


\section{9.}

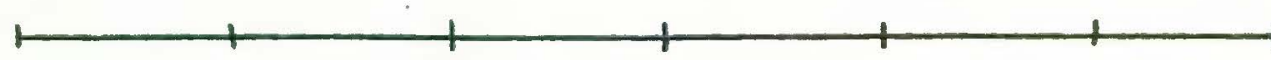

10.

11.

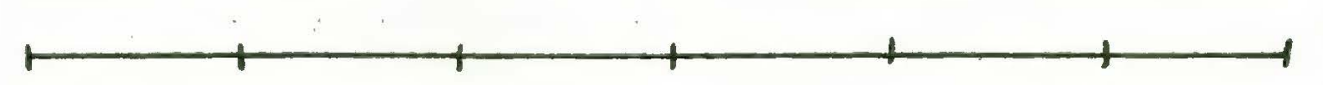

12.
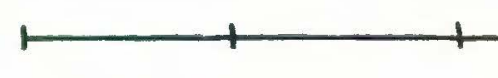

13.

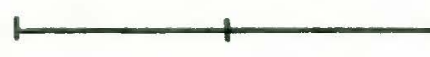

$(A-4)$

14.
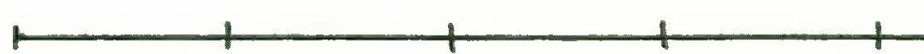

15.

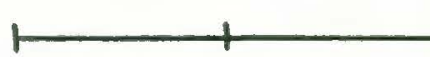

SECTION THREE:

GROUP \#I: A B B C $\quad \begin{aligned} & \text { (Order of volce presentation) } \\ & (\mathrm{A}-3 ; \mathrm{C}-1 ; \mathrm{B}-2)\end{aligned}$

GROUP \#2: $\mathrm{A}$

GROUP \#3: A B B B C C

GROUP \#4: A_B_C

GROUP \#5: A_ B_C___ (C-4; B-4; A-4)

GROUP \#6: A B B C C _ _ $\quad$ (A-I; B-2; C-2)

GROUP \#7: A B B C C

GROUP \#8: A B B C C _ (B-2; C-I; A-1)

GROUP \#9: A

GROUP \#IO: A B B C_C__ (B-2;A-3; C-3)

GROUP \#II: A B B C C _ _ $(\mathrm{C}-1 ; \mathrm{B}-2 ; \mathrm{A}-2)$

GROUP \#12: A B B B C C

GROUP \#13: A B_B_C__ (A-1; C-3; B-2)

GROUP \#I4: A B B C C

GROUP \#15: A B B C C _ C

GROUP \#16: A B B C C C (B-3; $A-2 ; C-1)$

GROUP \#17: A B B C C $(\mathrm{C}-2 ; \mathrm{B}-2 ; \mathrm{A}-2)$ 


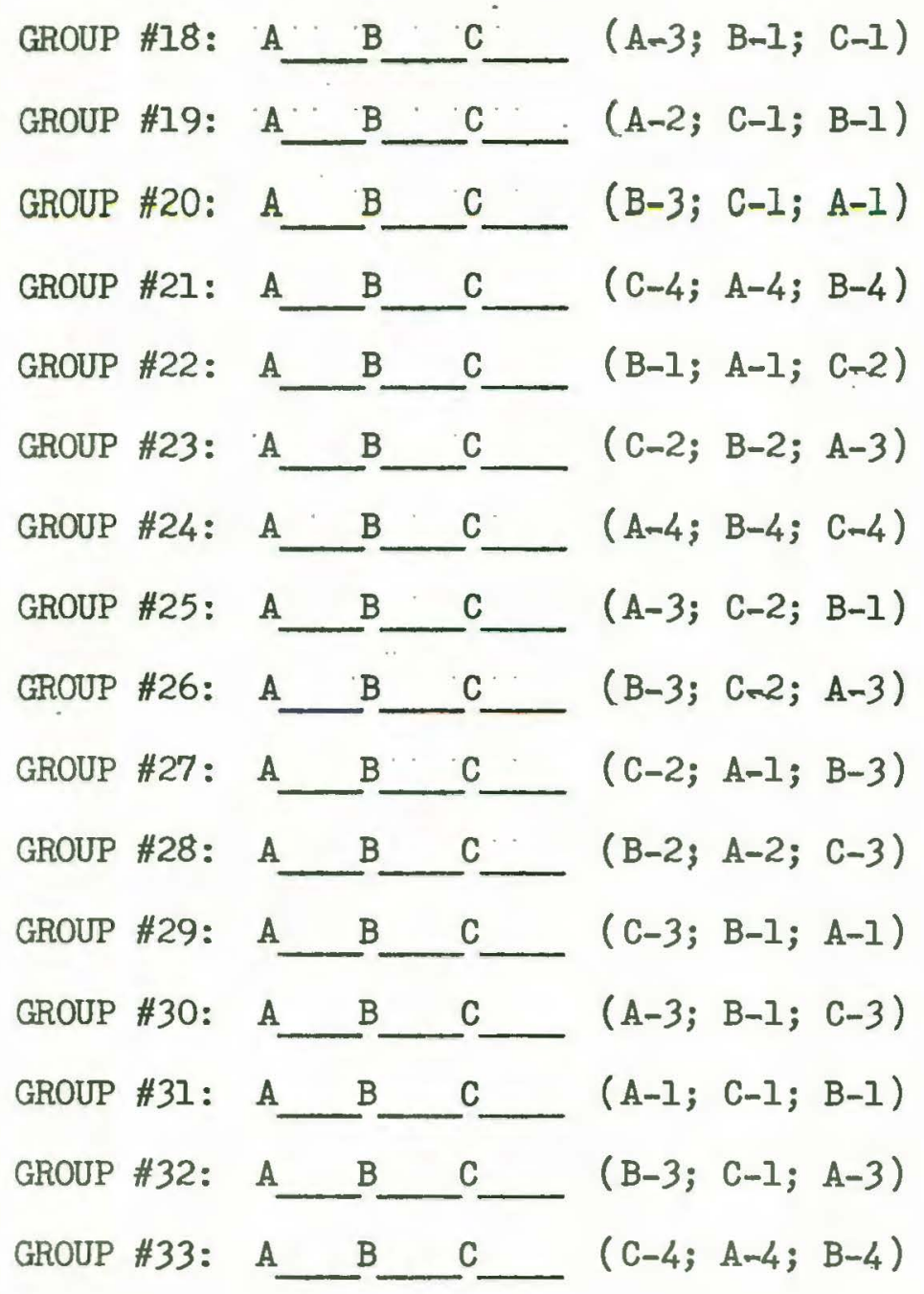


APPENDIX D

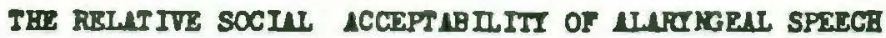
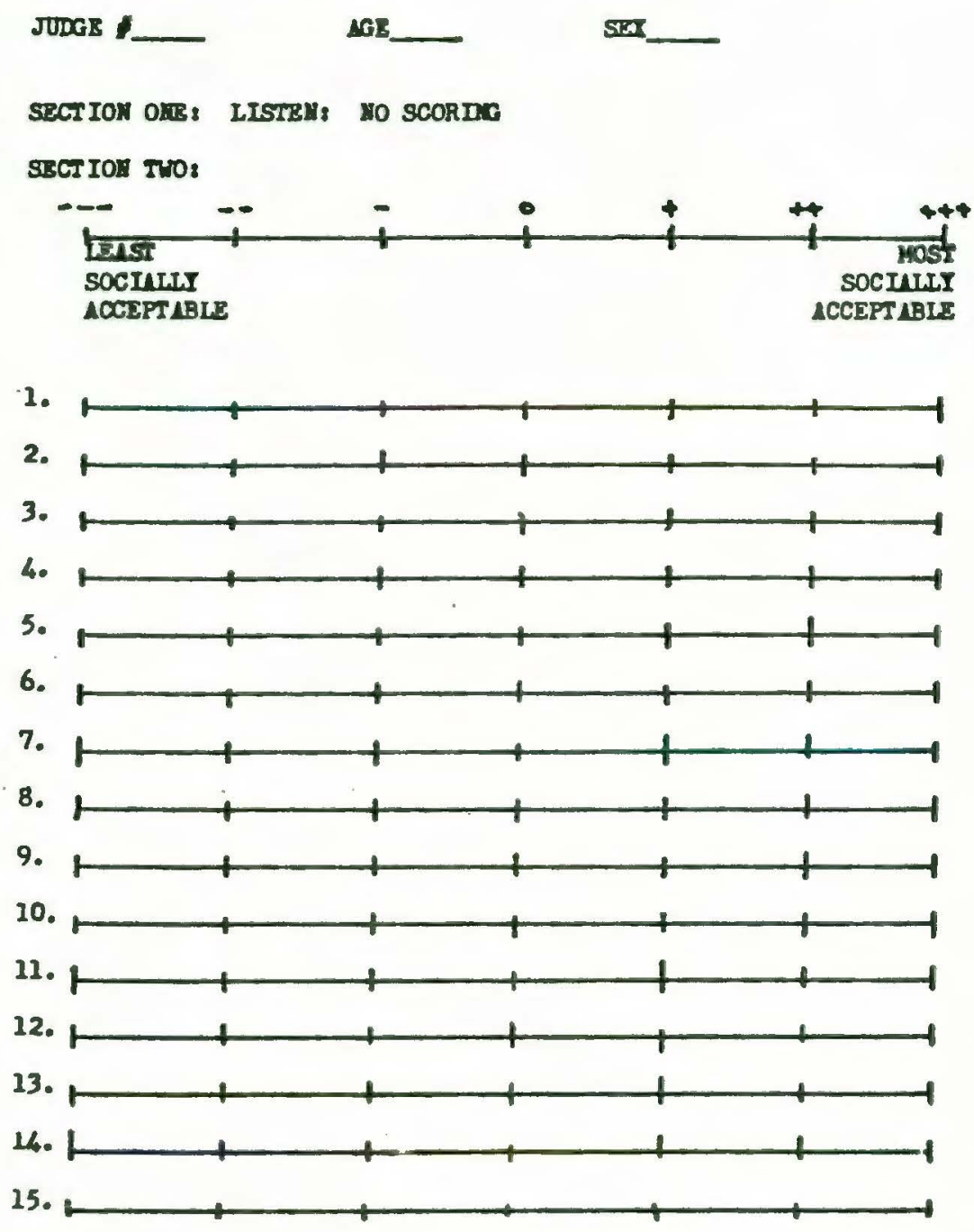

SECTIOU THRE: :

GROÖ $18 \quad A \quad B \quad B \quad C$

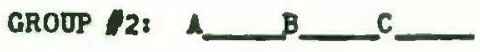

GROUP $3:$

GROOP 148 
SECT IOA TEREE (CONT.)

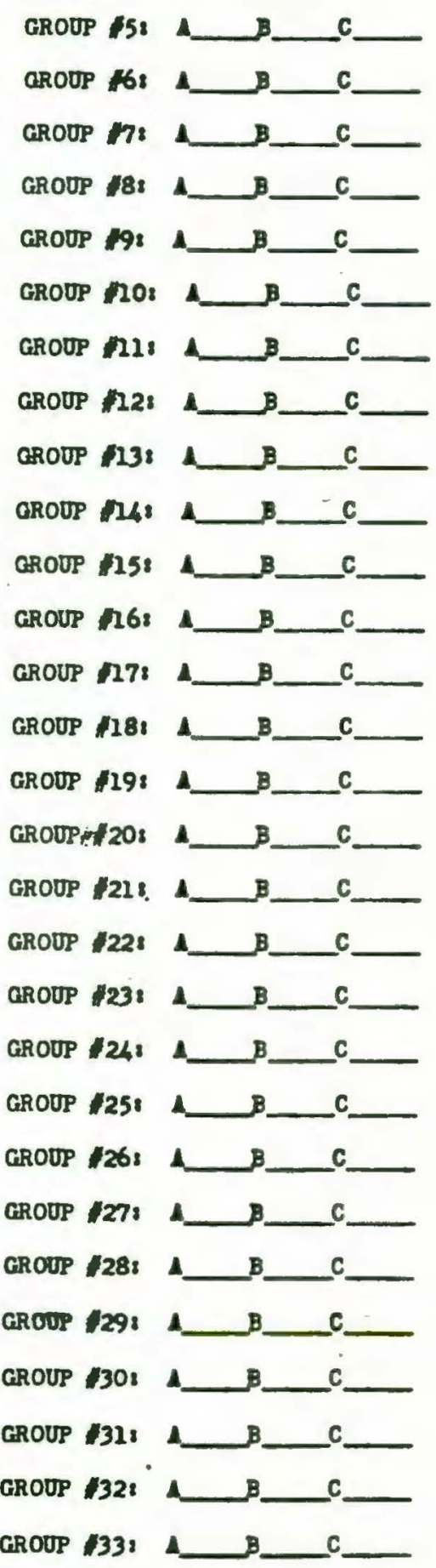


APPENDIX E

INSTRUCTIONS TO THE JUDGES

You are about to listen to a group of alaryngeal speakers. All of these speakers have had their larynges removed and have learned to speak again by a variety of methods. Seventy-five percent of the voices you will hear will be males. Occasionally you will be listening to female volces. Each speaker will be heard reading one sentence ("The rainbow is a division of white light into many beautiful colors.") The tape is divided into three sections. Listen to the first section to acquaint yourself with the range of voices. In sections two and three you will be asked to rate the voices on the parameter of social acceptability. Rating instructions will be given preceding sections two and three. Are there any questions?

Section one. Listen carefully to the following voices to acquaint yourself with the range of social acceptability. Do not do any rating. Just listen.

Section two. In this section each voice will be heard individually and rated on the seven point rating scale on your scoring sheets. Keeping in mind the range of voices you just heard in section one, rate each voice relative to the range of voices heard; with the three pluses at one end being the most socially acceptable and the three minuses being the least socially acceptable. Each voice will be preceded by the carrier phrase, voice number one, voịce number two, etc. You will be given 
five seconds between voices to rate them. Are there any questions?

Section three. In this section you will hear groups of voices. Each group will contain three voices. You are to listen to the voices and rank order their social acceptability; with 'one' being the most socially acceptable of the group, 'two' being the second most acceptable and 'three' being the least acceptable of the group. Each group will be played twice. Listen the first time to acquaint yourself with the volces in the group. Immediately following that presentation the voices will be presented again to rank order their social acceptability. Each group will be preceded by the carrier phrase, group number one, listen, group number one, rank order, etc. After hearing the voices the second time, you will be given five seconds to rank order their social acceptability. 